\title{
ANALISA LIGHTNING ARRESTER AKIBAT UPRATING TRANSFORMATOR 150/20 kV DARI 30 MVA KE 60 MVA DI GARDU INDUK SANUR
}

\author{
Dewa Putu Yudha Prawira ${ }^{1}$, I Gede Dyana Arjana ${ }^{2}$, Cok Gede Indra Partha ${ }^{3}$ \\ Program Studi Teknik Elektro, Fakultas Teknik, Universitas Udayana \\ Email : yudhadewaputu21@gmail.com ${ }^{1}{ }_{1}$ \\ dyanaariana@unud.ac.id ${ }^{2}$, cokindra@unud.ac.id ${ }^{3}$
}

\begin{abstract}
Abstrak
Salah satu Transformator di Gardu Induk Sanur mengalami uprating dari kapasitas 30 MVA menjadi 60 MVA. Bertambahnya kapasitas transformator tidak diikuti dengan uprating peralatan pengaman surja atau lightning arrester, sehingga perlu adanya kajian untuk mengetahui hal tersebut. Metode teori pantulan berulang dengan diagram tangga digunakan untuk mengetahui lightning arrester pada saat memotong kecuraman gelombang tegangan surja. Uprating Transformator diketahui berpengaruh terhadap lightning arrester. Lighning arrester pada transformator 30 MVA memiliki waktu percik 9,18 $\mu$ det, arus pelepasan 3,35 kA, dan tegangan kecuraman gelombang tertinggi tiba pada transformator $666,8 \mathrm{kV}$, sedangkan lighning arrester pada transformator 60 MVA memiliki waktu percik 8,14 $\mu$ det, arus pelepasan 3,98 kA, dan tegangan kecuraman gelombang tertinggi tiba pada transformator 816,8 kV atau sebesar 8,9\% diatas TID transformator tetapi tidak melewati standar yang diizinkan sebesar 20 $\%$ dari TID, Lightning arrester tidak diganti karena masih mampu mengisolasi transformator 60 MVA pada jarak tetap antara lightning arrester dengan transformator
\end{abstract}

Kata kunci :Surja, uprating transformator, lightning arrester, Gardu Induk Sanur.

Abstract
One of Transformer in Sanur Substation have uprating capacity from 30 MVA to 60 MVA. The capacity of transformer increasing not followed by uprating surge protection equipment or lightning arresters, so there needs to be a study to find out about it. The method using a theory of repeated reflection with ladder diagram to find out the lightning arrester when it was cutting voltage surge. Uprating of transformer has known to affect lightning arresters. The Lightning arresters in 30 MVA transformer has a spark time of $9.18 \mu$ det, discharge current is $3.35 \mathrm{kA}$, and the highest wave steepness voltage arrives in the transformer is $666.8 \mathrm{kV}$, while in the lighning arresters in 60 MVA transformer has a spark time of $8.14 \mu$ det, discharge current is $398 \mathrm{kA}$, and the highest wave steepness voltage arrives in the transformer is $816.8 \mathrm{kV}$ or $8.9 \%$ above the transformer BIL but not exceeding the standard allowed by $20 \%$ of TID. Lightning arresters are cannot be replaced because it is still able to isolate 60 MVA transformers in a fixed distance between lightning arresters and transformers

Keywords: Surge, transformer uprating, lightning arrester, Sanur Substation.

\section{PENDAHULUAN}

Gardu Induk Sanur berlokasi di daerah Sanur, terletak JIn Hangtuah Desa Sanur. Gardu Induk Sanur memegang peranan penting dalam mencukupi konsumsi energi listrik di wilayah sanur umumnya, serta sebagian wilayah kota Denpasar.

Gardu Induk Sanur mengalami uprating transformator, Transformator yang mengalami uprating yaitu Transformator 1 dari kapasitas 30 MVA menjadi 60 MVA dikarenakan dampak pertumbuhan beban yang semakin meningkat untuk daerah Sanur dan untuk meningkatkan keandalan transformator dalam melayani kebutuhan beban listrik. Bertambahnya kapasitas transformator tidak diikuti dengan uprating peralatan pengaman surja atau lightning arrester, sehingga perlu adanya kajian mengenai lightning arrester sebagai pengaman transformator. Lightning Arrester yang digunakan pada transformator 30 MVA merupakan lightning arrester yang 
sama untuk mengisolasi transformator Kemampuan lightning arrester sebagai pengaman surja pada transformator kapasitas 30 MVA dan kapasitas 60 MVA dapat diketahui menggunakan perhitungan matematis dan teori pantulan berulang, setelah mengetahui kemampuan lightning arrester kemudian membandingkan hasilnya untuk mengetahui lightning arrester dalam mengisolasi transformator 60 MVA, serta mengetahui juga pengaruh uprating transformator terhadap nilai arus pelepasan lightning arrester, waktu percik lightning arrester dan tegangan tertinggi yang tiba pada transformator. Oleh karena itu, perlunya mengetahui kemampuan lightning arrester akibat adanya uprating transformator di Gardu Induk Sanur, agar peralatan terhindar dari kerusakan ketika terjadi gangguan surja.

\section{KAJIAN PUSTAKA}

\subsection{Pengertian arester}

Lightning Arrester merupakan suatu peralatan listrik yang berfungsi untuk melindungi peralatan listrik lain dari tegangan surja (baik surja hubung maupun surja petir). Surja mungkin merambat di konduktor pada saat peristiwa sebagai berikut [9] :

a. Kegagalan sudut perlindungan petir, sehingga surja petir mengalir di dalam konduktor phasa.

b. Backflashover akibat nilai pentanahan yang tinggi, baik di saluran transmisi ataupun di gardu induk.

c. Proses switching DS atau CB (surja hubung).

d. Gangguan phasa-tanah, ataupun fasafasa baik pada di gardu induk maupun pada saluran transmisi.

Pada saat terjadi surja, travelling wave/gelombang berjalan merambat pada penghantar sistem transmisi dengan kecepatan mendekati kecepatan cahaya. Surja dengan panjang gelombang dalam orde mikro detik berbahaya jika nilai tegangan surja yang tiba di peralatan lebih tinggi dari level TID (Tingkat Isolasi Dasar) peralatan. Lightning Arrester dipasang untuk memotong tegangan surja dengan cara me-
MVA.

ngalirkan arus surja ke tanah dalam waktu yang sangat singkat, dimana pengaruh follow current tidak ikut serta diketanahkan $[3,[6],[9]$.

\subsection{Analisa kerja lightning arrester}

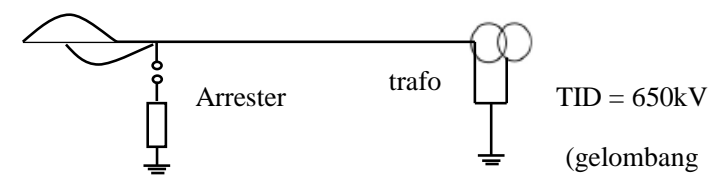

Gambar 1. Skema Sederhana Arrester Sambaran petir yang menyambar saluran dapat menyebabkan gelombang berjalan pada saluran kawat. Rambatan terdiri dari surja tegangan dan surja arus dengan kecepatan yang bergantung pada konstanta kawat saluran. Pada saat surja mencapai titik peralihan akan terjadi kenaikan pada gelombang tersebut sehingga terdapat beberapa perbedaan dengan gelombang asal [2].

Pada saat adanya tegangan lebih pada kawat fasa arrester sudah mulai bekerja pada saat tegangan yang masuk ke arrester sudah mencapai level 0,3 p.u sampai 0,5 p.u. Pada saat tegangan yang masuk ke arrester dan sudah mencapai angka 0,5 arrester harus sudah bekerja memotong tegangan lebih yang masuk dan langsung mengalirkannya ke tanah. Bila saat melewati angka 0,5 p.u arrester belum memotong tegangan lebih maka arrester di katakan gagal.

Besar impedansi surja untuk kawat udara $=400-600$ ohm, dan untuk kabel $=$ 50 - 60 ohm [2],[11].

\subsection{Tegangan Sistem Maksimum}

Tegangan sistem maksimum umumnya diambil harga $110 \%$ dari harga tegangan nominal sistem. Persamaannya dapat dilihat pada Persamaan 1 berikut [5]:

$$
\text { Vmax }=V_{\text {nominal }} \times 110 \% \text { (faktor toleransi) }
$$

Keterangan:

Vmax adalah Tegangan maksimum (V)

\subsection{Koefisien Pentanahan Arrester}

Sistem yang dibumikan secara langsung koefisien pembumiannya $(\eta)$ adalah 0,8 (arrester 80\%) [11]. 


\subsection{Tegangan Pengenal Lightning Arrester}

Tegangan pengenal arrester merupakan tegangan saat arrester dapat bekerja sesuai dengan karakteristiknya. Arrester tidak boleh bekerja saat tegangan maksimum sistem, tetapi mampu memutuskan arus susulan dari sistem dengan efektif. Persamaannya dapat dilihat pada Persamaan 2 berikut

$$
\mathrm{Ea}=\left(\mathrm{V}_{\text {nominal }} \times \eta\right) \times 110 \%
$$

Dimana,

Ea adalah Tegangan pengenal arrester V kerja arrester adalah Tegangan system $\chi$ adalah Koefisien Pentanahan arrester

\subsection{Arus Pelepasan}

Arus Pelepasan adalah besar puncak arus impuls $8 / 20 \mu$ s menurut standar, dan digunakan untuk mengklasifikasikan arrester .Berikut persamaan untuk menentukan arus pelepasan arrester dengan Persamaan 3 [5].

$$
\begin{gathered}
I a=\frac{2 E-E a}{Z+R} \\
R=\frac{\text { Tegangan Nominal }}{\text { Arus Nominal }}
\end{gathered}
$$

Keterangan:

la adalah arus pelepasan arester (A)

$\mathrm{E}$ adalah tegangan surja yang

datang $(\mathrm{kV})$

$\mathrm{Ea}$ adalah tegangan terminal arester (kV)

$\mathrm{Z}$ adalah Impedansi kawat transmisi $(\Omega)$ Impedansi surja (Surja Impedance)

$\mathrm{R}$ adalah resistansi Saluran $(\Omega)$

\subsection{Pemilihan Tingkat Isolasi Dasar}

Tingkat Isolasi Dasar (TID) menyatakan tingkat isolasi terhadap petir agar pemakaian arrester masih dalam koordinasi isolasi dan dapat memberikan hasil yang maksimal, sehingga perlu berpedoman pada beberapa asas. Pada Tabel 1 menunjukan perbandingan TID dengan tegangan sistem maksimum

Tabel 1. Perbandingan TID dengan tegangan

\begin{tabular}{|c|c|c|c|}
\hline Unom & $150 \mathrm{kV}$ & $275 \mathrm{kV}$ & $500 \mathrm{kV}$ \\
\hline Um & 170 & 300 & 550 \\
\hline BIL & 750 & 1050 & 1550 \\
\hline
\end{tabular}

Nilai puncak surja petir yang masuk ke pembangkit datang dari saluran yang dibatasi oleh TID saluran. Dengan mengingat variasi tegangan flasover dan probabilitas tembus isolator, maka 20\% untuk faktor keamanannya, sehingga harga Faktor Perlindunga (FP) pada Persamaan 5 [9].

$$
F P=1,2 \times T I D
$$

\subsection{Teori Penghitungan Jarak Maksimum}

\subsubsection{Penggunaan Teori Pantulan Berulang untuk Menentukan Jarak Maksimum Arrester dan Peralatan \\ Jarak maksimum antara arrester} dan peralatan atau panjang maksimum konduktor penghubung dapat ditentukan secara pendekatan dengan menggunakan teori pantulan berulang [11].

\subsubsection{Jarak Maksimum Arrester dan Transformator yang dihubung- kan dengan Saluran Udara \\ Skema jarak transformator dan arres-} ter dengan jarak $\mathrm{S}$ dapat dilihat pada Gambar 2 .

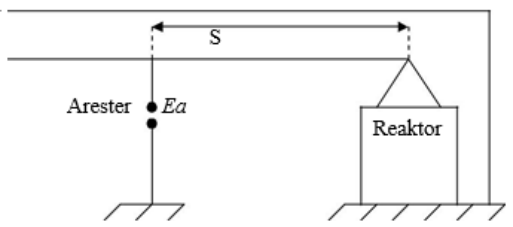

Gambar 2. Skema Jarak Lightning Arrester dan Transformator dengan Jarak

Perlindungan yang baik diperoleh apabila lightning arrester ditempatkan sedekat mungkin dengan transformator tetapi dalam praktek lightning arrester itu harus ditempatkan dengan jarak (S) dari transformator yang dilindungi, sehingga jarak tersebut ditentukan agar perlindungan dapat berlangsung dengan baik. Apabila lightning arrester mulai memercik, maka tegangan pada jepitan lightning arrester persamaannya dapat dilihat pada Persamaan 6 berikut [11]:

$$
\begin{aligned}
E a & =A t+A\left(t-\frac{S}{v}\right) \\
& =2 A t-2 A \frac{S}{v}
\end{aligned}
$$

Keterangan:

Ea adalah Tegangan percik arester (arester sparkover voltage)

Ep adalah TID

A (de/ dt) adalah kecuraman gelombang datang, dan dianggap kontan 
$S$ adalah Jarak antara arrester dengan trafo $v$ adalah kecepatan merambat gelombang t adalah waktu

Apabila waktu percik arrester $\mathrm{t}_{\mathrm{so}}$, dihitung mulai gelombang itu pertama kali sampai pada arrester, maka dari persamaan diatas menjadi Persamaan 7 [11].

$$
t_{s o}=\frac{E a+2 A S / v}{2 A}
$$

setelah terjadi suatu percikan maka arrester berlaku sebagai jepitan hubung singkat, dan menghasilkan gelombang. Berlkut pada Persamaan 8 [11].

$$
-A\left(t-t_{s o}\right)
$$

Gelombang negatif ini akan merambat ke transformator, dan setelah pantulan pertama pada transformator terjadi, jumlah tegangan pada transformator menjadi Persamaan 9 [11].

$$
\begin{aligned}
E p & =2 A t-2 A\left(t-t_{s o}\right)=2 A t_{s o} \\
& =2 A \frac{E a+2 A s / v}{2 A}=E a+2 A S / v
\end{aligned}
$$

Harga maksimum Ep adalah 2 Ea.

Apabila tegangan tembus isolator transformator $=\mathrm{Ep}$, maka $\mathrm{Ep}$ harus lebih besar dari $(\mathrm{Ea}+2 \mathrm{AS} / \mathrm{v})$ agar diperoleh perlindungan yang baik. Untuk mengubah harga Ep cukup dengan mengubah $S$. Semakin kecil S maka makin kecil pula Ep.

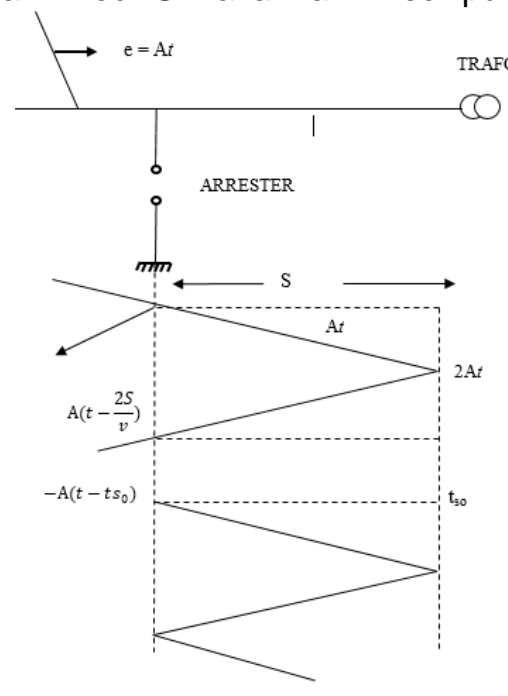

Gambar 3. Simulasi Diagram Tangga Perlindungan Lightning Arrester terhadap Transformator

Hasil dari persamaan kemudian dianalisis dengan teori pantulan berulang untuk menentukan jarak maksismum arester dan peralatan. Analisis menggunakan diagram tangga untuk dapat mengikuti jejak gelombang itu pada waktu tertentu, dibawah ini dapat dilihat pada
Gambar 3. diagram tangga suatu gelombang surja yang melalui lightning arrester dan transformator.

Waktu Percik Arrester $\left(t_{a o}\right)$ :

$$
t_{a o}=8+\Delta t
$$

\section{METODE PENELITIAN}

\subsection{Analisis Data}

Penelitian ini dilakukan di PT. PLN (Persero) Transmisi Jawa Bagian Timur dan Bali APP Bali dan Gardu Induk Sanur. Proses penelitian ini dimulai pada tanggal 23 November 2017.

Tahapan menganalisis data yang digunakan sebagai berikut

1. Menentukan tegangan pengenal lightning arrester:

2. Menentukan arus pelepasan lightning arrester

3. Menentukan Jarak Lightning Arrester ke Transformator dengan perhitungan koordinasi lokasi arester sesuai dengan teori Hutauruk

4. Menentukan Karakteristik Lokasi Lightning Arrester dengan Tingkat Isolasi Peralatan yang Dilindungi Menggunakan Teori Pantulan Berulang

5. Menentukan waktu percik arrester dan Tegangan Tertinggi yang tiba pada Transformator

6. Mengetahui mampukah Lightning Arrester megisolir gangguan surja, sehingga transformator tetap aman

\subsection{Alur Penelitian}

Adapun alur tahapan penelitian yang dilakukan pada penelitian ini dapat dilihat pada Gambar 4. dibawah ini: 


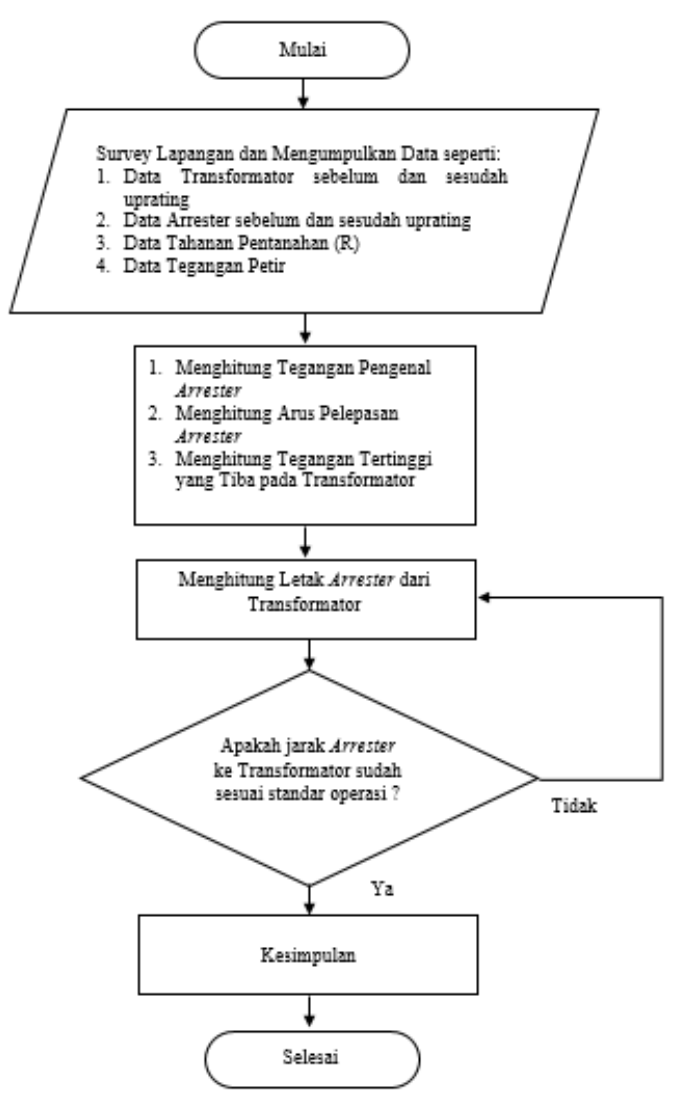

Gambar 4. Alur Tahapan Penelitian

\section{HASIL DAN PEMBAHASAN}

Mengetahui pengaruh uprating transformator 150/20 kV terhadap Lightning Arrester di Gardu Induk dengan membandingkan ketika terpasang transformator kapasitas 30 MVA dengan yang sekarang transformator 60 MVA

\subsection{Pemilihan Lightning Arrester sebagai Pelindung Petir pada Transformator 30 MVA \\ 4.1.1 Menentukan Tegangan Sistem Maksimum}

Menentukan Tegangan sistem maksimum dengan Persamaan 1:

$V m=V_{\text {nominal }} \times 110 \%$ (faktor toleransi)

$$
=150 \mathrm{kV} \times 1,1
$$$$
=165 \mathrm{kV}
$$

Berdasarkan standar PLN dan hasil penelitian yang dilakukan di lapangan, tegangan sistem maksimum dapat mencapai $170 \mathrm{kV}$. Sehingga digunakan tegangan sistem tertinggi sebesar $170 \mathrm{kV}$.

\subsubsection{Menentukan \\ Pengenal Arrester}

Tegangan

Tegangan pengenal ditentukan menggunakan Persamaan 2 sebagai berikut

$$
\begin{aligned}
\mathrm{E}_{\mathrm{a}} & =(150 \mathrm{kV} \times 0,8) \times 1,1 \\
& =135 \mathrm{kV}
\end{aligned}
$$

Berdasarkan perhitungan menentukan Tegangan pengenal lightning arrester didapatkan tegangan sebesar $135 \mathrm{kV}$, tetapi lightning arrester dengan nilai tegangan pengenal $135 \mathrm{kV}$ tidak ada, sehingga digunakan tegangan pengenal dengan nilai arrester rating $138 \mathrm{kV}$, dapat dilihat pada Tabel 2. sebagai berikut.

Tabel 2. Harga Maksimum Tegangan Lebih Gelombang Petir

\begin{tabular}{|c|c|c|c|}
\hline $\begin{array}{l}\text { Arrester } \\
\text { rating kV } \\
\text { rms }\end{array}$ & $\begin{array}{l}\text { Front } \\
\text { steepness } \\
\text { FOW } \\
\mathrm{kV} / \mu \mathrm{s}\end{array}$ & $\begin{array}{l}\text { l } \\
\mathrm{kA} \text {, } \\
\text { Serie A }\end{array}$ \\
\cline { 2 - 4 } & Std. kV, peak & FOW.kV, peak \\
\hline 1 & 2 & 3 & 4 \\
\hline 108 & 870 & 363 & 418 \\
\hline 120 & 940 & 940 & 463 \\
\hline 126 & 980 & 420 & 495 \\
\hline 138 & 1.030 & 500 & 577 \\
\hline 174 & 1.160 & 570 & 660 \\
\hline 186 & 1.180 & 610 & 702 \\
\hline 198 & 1.200 & 649 & 746 \\
\hline
\end{tabular}

Sumber : PT PLN (Persero)

\subsubsection{Menentukan tegangan percikan impuls maksimum}

Menentukan besarnya nilai tegangan percikan impuls maksimal ligtning arrester dengan tegangan operasi pada sistem 150 $\mathrm{kV}$, maka dengan menggunakan Tabel 4.1 karakteristik arrester diperoleh tegangan percikan impuls maksimum sebesar $577 \mathrm{kV}$

4.1.4 Menentukan Arus Pelepasan Lightning Arrester pada Transformator $30 \mathrm{MVA}$

Arus pelepasan Lightning Arrester dapat ditentukan dengan menggunakan persamaan 3 .

Besar impedansi surja untuk kawat udara $=$ $400-600$ ohm, dan untuk kabel $=50-60$ ohm (Hutauruk 1989:4).

a. Arus Nominal Transformator 30 MVA

Arus nominal transformator 30 MVA pada gardu induk Sanur diperoleh data sebesar 866 A.

b. Menentukan Hambatan Saluran Hambatan Saluran transformator 30 MVA pada gardu induk Sanur dapat ditentukan menggunakan Persamaan 4 sebagai berikut

$$
\begin{aligned}
R & =\frac{150 \mathrm{kV}}{866 \mathrm{~A}} \\
& =173 \Omega
\end{aligned}
$$

c. Menentukan Arus Pelepasan Arus Pelepasan Lightning Arrester untuk mengisolasi transformator dengan kapasitas 30 MVA 
diperoleh hasil melalui perhitungan menggunakan Persamaan 3 sebagai berikut:

$$
\begin{aligned}
& I a=\frac{2(1030)-138}{400+173} \\
& I a=3,35 \mathrm{kA}
\end{aligned}
$$

\subsubsection{Menentukan Arus Pelepasan Lightning Arrester pada Transformator 60 MVA}

Arus pelepasan Lightning Arrester dapat ditentukan dengan menggunakan persamaan 3.

Besar impedansi surja untuk kawat udara $=$ $400-600$ ohm, dan untuk kabel $=50-60$ ohm [11].

a. Arus Nominal Transformator 60 MVA

Arus nominal transformator 60 MVA pada gardu induk Sanur diperoleh data sebesar $1732 \mathrm{~A}$.

b. Menentukan Hambatan Saluran Hambatan Saluran transformator 60 MVA pada gardu induk Sanur dapat ditentukan menggunakan Persamaan 4 sebagai berikut

$$
\begin{aligned}
R & =\frac{150 \mathrm{kV}}{1732 \mathrm{~A}} \\
& =86 \Omega
\end{aligned}
$$

c. Menentukan Arus Pelepasan Arus Pelepasan Lightning Arrester untuk mengisolasi transformator dengan kapasitas 60 MVA diperoleh hasil melalui perhitungan menggunakan Persamaan 3 sebagai berikut:

$$
\begin{aligned}
& I a=\frac{2(1030)-138}{400+86} \\
& I a=3,96 \mathrm{kA}
\end{aligned}
$$

\subsection{Karakteristik Lokasi Lightning Arrester dengan Tingkat Isolasi Peralatan yang Dilindungi Menggunakan Teori Pantulan Berulang}

4.2.1 Karakteristik Lokasi Lightning Arrester dengan Tingkat Isolasi Transformator

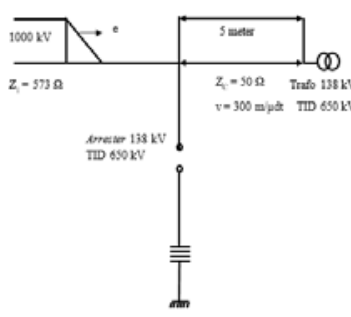

(a)

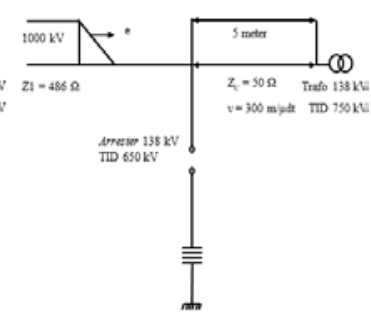

(b)
Gambar 5.(a) Konstruksi Perlindungan Lightning Arrester terhadap Transformator 30 MVA, (b) Konstruksi Perlindungan Lightning Arrester terhadap Transformator 60 MVA

\subsubsection{Perhitungan Jarak Lightning Arrester dengan Transformator \\ Data mengenai penelitian dapat} dilihat pada tabel 3. Dan Tabel 4. berikut

Tabel 3. Data Eksisting Penelitian pada Transformator $30 \mathrm{MVA}$

\begin{tabular}{|c|c|c|c|c|c|}
\hline $\begin{array}{c}\text { Tegangan } \\
\text { sistem } \\
(\mathrm{kV})\end{array}$ & $\begin{array}{c}\text { Transformator } \\
(\mathrm{kV})\end{array}$ & $\begin{array}{c}\text { Lightning } \\
\text { Arrester } \\
(\mathrm{kV})\end{array}$ & $\begin{array}{c}\text { Tegangan } \\
\text { Percik } \\
(\mathrm{kV})\end{array}$ & $\begin{array}{c}\text { Jarak Arrester } \\
\text { ke } \\
\text { Transfotmator } \\
(\mathrm{m})\end{array}$ & $\begin{array}{c}\text { Kecepatan } \\
\text { Rambat } \\
\text { Surja } \\
(\mathrm{m} / \mu \mathrm{det})\end{array}$ \\
\hline 150 & 650 & 650 & 577 & 5 & 300 \\
\hline
\end{tabular}

Tabel 4. Data Hasil Penelitian pada transformator $60 \mathrm{MVA}$

\begin{tabular}{|c|c|c|c|c|c|}
\hline $\begin{array}{c}\text { Tegangan } \\
\text { sistem } \\
(\mathrm{kV})\end{array}$ & $\begin{array}{c}\text { Transformator } \\
(\mathrm{kV})\end{array}$ & $\begin{array}{c}\text { Tightning } \\
\text { Arrester } \\
(\mathrm{kV})\end{array}$ & $\begin{array}{c}\text { Tegangan } \\
\text { Percik } \\
(\mathrm{kV})\end{array}$ & $\begin{array}{c}\text { Jarak Arrester } \\
\text { ke } \\
\text { Transfotmator } \\
(\mathrm{m})\end{array}$ & $\begin{array}{c}\text { Kecepatan } \\
\text { Rambat } \\
\text { Surja } \\
(\mathrm{m} / \mu \mathrm{det})\end{array}$ \\
\hline 150 & 750 & 650 & 577 & 5 & 300 \\
\hline
\end{tabular}

Sumber: PT. PLN (Persero) Gardu Induk Sanur

Dari data yang diperoleh pada Tabel 3. dan 4. dapat ditentukan jarak maksimum antara Lightning Arrester terhadap Transformator,

Diketahui:

Tegangan Percik Arrester

(Ea) adalah $577 \mathrm{kV}$

Tingkat Isolasi Dasar Arrester

(Ep) adalah $650 \mathrm{kV}$

Kecuraman Gelombang datang

(A) adalah $1000 \mathrm{dv} / \mathrm{dt}$

Kecepatan Rambat Gelombang adalah $300 \mathrm{~m} / \mu \mathrm{det}$

Surja datang dengan kecuraman gelombang $1000 \mathrm{dv/dt}$, sehingga dapat ditentukan jarak maksimum arrester menggunakan persamaan berikut

$$
\begin{aligned}
E p= & E a+2 \frac{A . S}{v} \\
650= & 577+2 \frac{1000 S}{300} \\
73= & 2 \frac{1000 S}{300} \\
& S=\frac{73}{6,66}=10,44 \text { meter }
\end{aligned}
$$

Jadi jarak menurut perhitungan antara arrester dengan transformator adalah 10,44 meter, Pada kenyataannya di lapangan dipasang sejauh 5 meter, sehingga pemasangannya masih di bawah harga maksimum. 


\subsubsection{Analisis Menggunakan Teori Pantulan Berulang pada Lightning Arrester Sebagai Proteksi Surja untuk Transformator 30 MVA}

1. $a=\frac{Z c-Z 1}{Z c+Z 1}=\frac{50-573}{50+573}=\frac{-523}{623}=-0,84$

2. $a^{\prime}=\frac{2 Z c}{Z c+Z 1}=\frac{2 \cdot 50}{50+573}=\frac{100}{623}=0,16$

3. $b=\frac{Z 1-Z c}{Z 1+Z c}=\frac{573-50}{573+50}=\frac{523}{623}=0,84$

4. $b^{\prime}=\frac{2 Z 1}{Z 1+Z c}=\frac{2 \cdot 573}{573+50}=\frac{1146}{623}=1,84$ Keterangan:

a adalah pantulan gelombang yang datang dari kiri a' adalah pantulan gelombang yang datang dari kanan $b$ adalah terusan gelombang yang datang dari kiri $b$ ' adalah terusan gelombang yang datang dari kanan

\subsubsection{Waktu Percik Arrester $\left(t_{a o}\right)$ :}

$$
t_{a o}=8+\Delta t
$$

Diperoleh $t_{a o}$ sebagai berikut:

$$
\begin{gathered}
577=446,7+1,84 \times \frac{126,7}{2} \Delta t \\
130,3=1,18 \\
\Delta t=8
\end{gathered}
$$

Jadi $t_{\mathrm{ao}}=8+\Delta t=8+1,18=9,18 \mu \mathrm{det}$

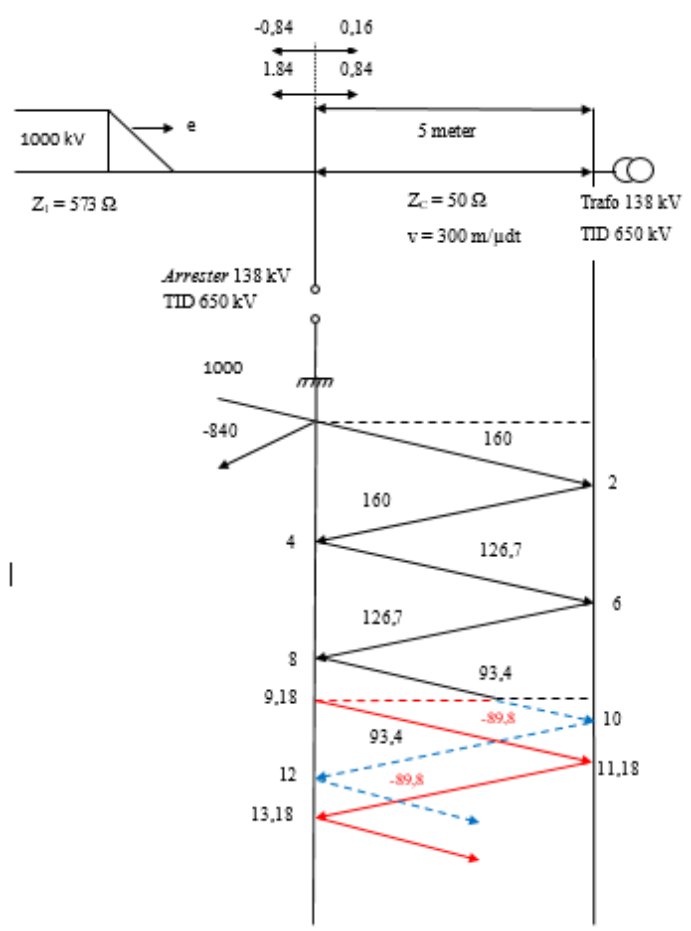

Gambar 6. Diagram Tangga Kecuraman Gelombang Surja pada Lightning Arrester dan Transformator 30 MVA
Pertama-tama harus menentukan waktu pada saat dimana lightning arrester mengalami percikan, maka tegangan yang timbul pada titik sambungan saluran udara. $\mathrm{t}=0 \mu \mathrm{det} ; e=0$

$\mathrm{t}=2 \mu \mathrm{det} ; \mathrm{e}=160 \mathrm{kV}$

$\mathrm{t}=4 \mu \mathrm{det} ; \mathrm{e}=160 \mathrm{kV}$

$\mathrm{t}=6$ udet; $e=160+160+126,7=446,7$ $\mathrm{kV}$

$\mathrm{t}=8 \mu \mathrm{det} ; \mathrm{e}=446,7 \mathrm{kV}$

$\mathrm{t}=10 \mu$ det; $e=160+160+126,7+126,7+$ $\mathrm{t}=12 \mu \mathrm{det} ; \mathrm{e}=666,8 \mathrm{kV}$

Tabel 5. Hasil Perhitungan Kecuraman Gelombang Berdasarkan Waktu

\begin{tabular}{|c|c|c|}
\hline No. & $\begin{array}{c}\text { Waktu } \\
(\mu \text { det })\end{array}$ & $\begin{array}{c}\text { Kecuraman Gelombang } \\
(\mathrm{kV})\end{array}$ \\
\hline 1 & 0 & 0 \\
\hline 2 & 2 & 160 \\
\hline 3 & 4 & 160 \\
\hline 4 & 6 & 446,7 \\
\hline 5 & 8 & 446,7 \\
\hline 6 & 10 & 666,8 \\
\hline 7 & 12 & 666,8 \\
\hline
\end{tabular}

Naiknya nilai tegangan pada lokasi arrester diberikan dalam Gambar 7. sesuai perhitungan waktu arrester di bawah ini:

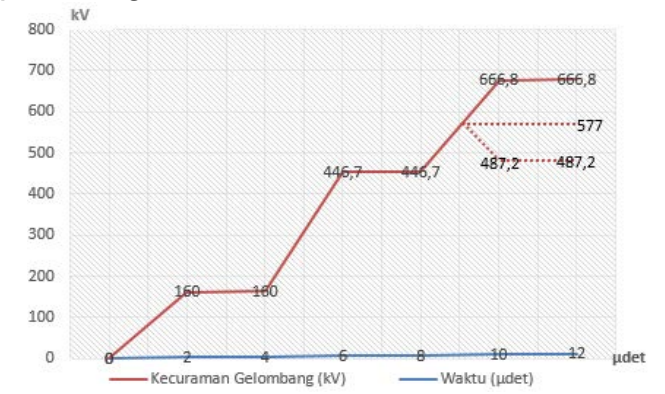

Gambar 7. Grafik Pemotongan Kecuraman Gelombang pada Waktu Percik 9,18 $\mu$ det

\subsection{Analisis Menggunakan Teori Pantulan Berulang pada Lightning Arrester dalam mengisolasi Transformator 60 MVA \\ Analisis dengan Menggunakan cara} yang sama ketika menganalisis lightninf arrester dalam mengisolasi transformator 30 MVA pada sub bab 4.2.3 akan diperoleh hasil pada transformator 60 MVA sebagai berikut

Tabel 6. Hasil Perhitungan Kecuraman Gelombang Berdasarkan Waktu 


\begin{tabular}{|c|c|c|}
\hline No. & $\begin{array}{c}\text { Waktu } \\
(\mu \mathrm{det})\end{array}$ & $\begin{array}{c}\text { Kecuraman Gelombang } \\
(\mathrm{kV})\end{array}$ \\
\hline 1 & 0 & 0 \\
\hline 2 & 2 & 190 \\
\hline 3 & 4 & 190 \\
\hline 4 & 6 & 536,7 \\
\hline 5 & 8 & 536,7 \\
\hline 6 & 10 & 816,8 \\
\hline 7 & 12 & 816,8 \\
\hline
\end{tabular}

Naiknya nilai tegangan pada lokasi arrester diberikan dalam Gambar 8. Sesuai perhitungan waktu arrester di bawah ini:

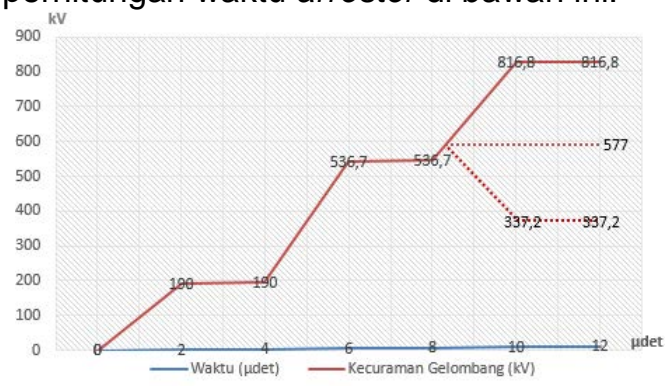

Gambar 8. Grafik Pemotongan Kecuraman Gelombang pada Waktu Percik 8,14 $\mu$ det

Berikut adalah hasil perhitungan faktor perlindungan pada transformator 30 MVA dengan menggunakan Persamaan 5.

$$
\begin{aligned}
F P & =1,2 \times \mathrm{TID} \\
F P & =1,2 \times 650 \\
& =780 \mathrm{kV}
\end{aligned}
$$

sehingga untuk tegangan kecuraman gelombang yang tertinggi tiba pada transformator sebesar $666,8 \mathrm{kV}$ belum melewati batas toleransi TID transformator sebesar $780 \mathrm{kV}$.

TID transformator kapasitas 60 MVA adalah sebesar $750 \mathrm{kV}$, sedangkan tegangan yang timbul puncaknya sampai 816,8 kV pada $10 \mu$ det, maka lightning arrester masih mampu melindungi transformator dengan standar maksimal $20 \%$ dari TID. Berikut adalah hasil perhitungan faktor perlindungan pada transformator 60 MVA.

$$
\begin{aligned}
F P & =1,2 \times T I D \\
F P & =1,2 \times 750 \\
& =900 \mathrm{kV}
\end{aligned}
$$

sehingga untuk tegangan kecuraman gelombang yang tertinggi tiba pada transformator sebesar $816,8 \mathrm{kV}$ belum melewati batas toleransi TID transformator sebesar $900 \mathrm{kV}$.

Analisis pengaruh dari adanya uprating Transformator 150/20 kV terhadap Lightning Arrester di Gardu Induk Sanur dapat dilakukan setelah melakukan perhitungan secara matematis pada pembahasan diatas. Hasil dari perhitungan yang diperoleh dapat dilihat pada Tabel 7 . sebagai berikut.

Tabel 7. Data Perbandingan Hasil Perhitungan

\begin{tabular}{|c|c|c|c|}
\hline \multirow{2}{*}{ No } & Data Peralatan & \multicolumn{2}{|c|}{ Transformator } \\
\cline { 3 - 4 } & 1 & 30 MVA & 60 MVA \\
\hline 2 & Jarak LA ke Transformator (m) & 5 & 5 \\
\hline 3 & TID Transformator (kV) & 650 & 750 \\
\hline 4 & $\begin{array}{c}\text { Tegangan Percik Lightning } \\
\text { Arrester }(k V)\end{array}$ & 577 & 577 \\
\hline 5 & $\begin{array}{c}\text { Tegangan Tertinggi Tiba di } \\
\text { Trafo }\end{array}$ & 666,8 & 816,8 \\
\hline 6 & Arus Pelepeasan (kA) & 3,35 & 3,98 \\
\hline 7 & $\begin{array}{c}\text { Waktu Percik Lightning Arrester } \\
\text { ( } \mu \text { det) }\end{array}$ & 9,18 & 8,14 \\
\hline
\end{tabular}

5

KESIMPULAN

Lightning arrester pada transformator 30 MVA memiliki waktu percik selama 9,18 $\mu d e$, arus pelepasan sebesar $3,35 \mathrm{kA}$, dan tegangan kecuraman gelombang tertinggi tiba pada transformator sebesar $666,8 \mathrm{kV}$, sedangkan pada lighning arrester transformator 60 MVA memiliki waktu percik selama 8,14 $\mu \mathrm{det}$, arus pelepasan sebesar 3,98 kA, dan tegangan kecuraman gelombang tertinggi tiba pada transformator sebesar 816,8 kV. Jadi berdasarkan hasil penelitian dapat diketahui bahwa semakin besar kapasitas transformator, maka waktu percik arresternya semakin cepat untuk memotong tegangan surja yang merambat. Uprating transformator memiliki pengaruh juga terhadap arus pelepasan arrester. Meskipun nilai arus pelepasan arrester mengalami kenaikan, akan tetapi arrester masih baik dalam mengisolasi transformator dari surja, karena nilai arus pelepasan pada arrester yang terpasang sebesar $10 \mathrm{kA}$. Uprating transformator memiliki pengaruh juga terhadap tegangan kecuraman gelombang tertinggi tiba pada transformator, akan tetapi lightning arrester masih mampu melindungi transformator dengan standar maksimal $20 \%$ dari TID. Uprating Transformator memiliki pengaruh terhadap lightning arrester di Gardu Induk Sanur, tetapi faktor perlindungannya masih dibawah standar maksimum yang diizinkan dan Lightning Arrester tidak perlu diganti sehingga dapat menghemat biaya., karena arrester tersebut masih mampu untuk mengisolasi transformator $60 \mathrm{MVA}$. 
6 DAFTAR PUSTAKA

[1] IEEE/IEC Lightning Arresters Class 4 Ratings. IEC60099-4 CLASS 4 IEEE C62.11. IEEE/IEC Lightning Arrester, Arresters for $A C$ and $D C$ Application. GE Digital Energy. 2015.

[2] Bandri, Sepannur. Analisa Gangguan Petir Sutt 150 kV Dengan Memperhatikan Tegangan Pada Lightning Arrester Dan Trafo. Tugas Akhir. Padang: Institut Teknologi Padang. 2015.

[3] Hidayatulloh, N. Kemampuan Arester. Untuk Pengaman Tranformator Pada Gardu Induk Srondol 150 kV. Tugas

[7] Parera, L. M. Analisis Perlindungan Transformator Distribusi Yang Efektif Terhadap Surja Petir Tugas Akhir. Ambon: Politeknik Negri Ambon.

[8] Rezon Arif B. Lightning Arrester. Semarang: Universitas Diponogoro. 2010.

[9] Rusdjaja, Tatang. Buku Pedoman Pemeliharaan Lightning Arrester (LA).Jakarta Selatan: PT PLN (Persero). 2010.

[10]Team O \& M. Operasi dan Memelihara Peralatan". Jawa Barat dan Jakarta: PLN Pembangkitan. 1981

[11]T. S. Hutauruk. "Gelombang Berjalan dan Proteksi Surja". Jakarta: Erlangga. 1991.
Akhir. Semarang: Universitas Negeri. 2009.

[4] Hinrichsen, Volker. Metal-Oxide Surge Arresters in High-Voltage Power Systems. Germany: Siemens. 2012.

[5] Kelompok Bidang Transmisi Standardisasi. Spesifikasi Arrester Untuk Jaringan Transmisi $66 \mathrm{kV}, 150$ $k V, 275 k V$ DAN 500 kV. Jakarta Selatan: PT PLN (Persero). 2014.

[6] Kholis, Nur. Unjuk Kerja Arester Type HImn 136 Untuk Pengamanan Reaktor 7r1 Pada Gardu Induk 500 kV Di Upt Semarang. Tugas Akhir. Semarang: Universitas Diponogoro. 2006. 